\title{
A Simple Spectrophotometric Determination of Rebeprazole in Pharmaceutical Preparations
}

\author{
M. RAMESH KUMAR ${ }^{\mathrm{a}}$, T. SREENIVASULU REDDY ${ }^{\mathrm{b}}$ and K. PRABHAVATHI \\ ${ }^{\mathrm{a} D e p a r t m e n t ~ o f ~ C h e m i s t r y, ~ T h e ~ A d o n i ~ A r t s ~ a n d ~ S c i e n c e ~ C o l l e g e, ~ A d o n i, ~}$ \\ Kurnool (Dt), A.P, India \\ ${ }^{\mathrm{b}}$ Department of Chemistry, S.K. University, Anantapur (Dt), A.P, India \\ *Department of Chemistry, S.B.S.Y.M. Degree College, Kurnool (Dt), A.P, India \\ katamprabhavathi@gmail.com
}

Received 2 July 2012 / Accepted 28 July 2012

\begin{abstract}
A simple, sensitive spectrophotometric method was developed for the determination of rabeprazole in pure form and for pharmaceutical formulations. In this method 2,3-dichloro-5, 6-dicyano-p-benzoquinone (DDQ) was utilized for determination of rabeprazole forming charge transfer complex with maximum absorbance at $\lambda_{\max } 460 \mathrm{~nm}$. Variables affecting the reaction were studied and optimized. Beer's law was obeyed in concentration range $20-100 \mu \mathrm{g} / \mathrm{mL}$ for rabeprazole. The accuracy and reproducibility of the proposed method was statistically validated by recovery studies. The proposed method is simple, rapid and validated and can be used successfully for routine analysis of rabeprazole in a pure and tablet dosage form.
\end{abstract}

Keywords: Rabeprazole, 2, 3-Dichloro-5, 6-dicyano-p-benzoquinone, Pharmaceutical formulations, DDQ, Determinations

\section{Introduction}

Rabeprazole (RA), or 2-[[[4-(3-methoxypropoxy)-3-methyl-2-pyridinyl]-methyl]sulphinyl]-1H benzimidazole, is a selective and irreversible proton pump inhibitor suppressing gastric acid secretion by specific inhibition of the gastric hydrogen-potassium adenosine triphosphatase enzyme system at the secretory surface of the gastric parietal cells. It inhibits the final transport of hydrogenions (via exchange with potassium ions) into the gastric lumen. Rabeprazole is not officially listed in any pharmacopoeia. Literature survey revealed that capillary electrophoresis method ${ }^{1}$, liquid chromatography- tandem mass spectrometry ${ }^{2}$, RPHPLC method ${ }^{3,4}$, spectrophotometric and chromatographic determination, ${ }^{5}$ spectrophotometric method ${ }^{6-8}$ were reported for determination of rabeprazole in tablet dosage forms. Various methods were reported in literature for determination of rabeprazole in combination with other drugs which includes, HPLC method ${ }^{9-14}$, HPTLC method ${ }^{15-17}$, column reversed-phase high-performance liquid chromatographic method ${ }^{18}$, spectrophotometric method $^{19-30}$. 
This work describes a simple visible spectrophotometric method for the determination of rabeprazole by exploiting its basic nature and electron donating property. This method is based on the charge transfer complexation reaction of rabeprazole with 2,3-dichloro-5, 6-dicyano-p-benzoquinone (DDQ) in methanol medium. Therefore, the need for a fast, simple, sensitive, low-cost and selective method is obvious, especially for a routine quality control analysis of rabeprazole in drug formulations.

\section{Experimental}

All absorbance measurements were made on a Spectronic 1001 plus spectrophotometer (Milton Roy Company, USA) with $1 \mathrm{~cm}$ matched quartz cells.

\section{Chemicals and reagents}

All the solutions were freshly prepared. All solvents and other chemicals used through this study were of analytical grade. 2,3-Dichloro 5,6-dicyano-p-benzoquinone(DDQ; Merck, Schuchardt, Munich, Germany) solution(0.1\%) solution was freshly prepared in methanol and it was prepared a fresh daily.

\section{Preparation of standard stock solution}

Stock solution of rabeprazole was prepared by transferring $50 \mathrm{mg}$ of rabeprazole to a $50 \mathrm{~mL}$ standard flask and diluting it up to the mark with methanol. From the stock solution, a working standard solution containing $100 \mu \mathrm{g} / \mathrm{mL}$ was prepared for the proposed method.

Assay

Aliquots of rabeprazole solution $(0.2-1.0 \mathrm{~mL})$ were placed in $10 \mathrm{~mL}$ standard volumetric flasks. To each flask, $1.5 \mathrm{~mL}$ of $0.1 \%$ DDQ was added and diluted up to the mark with methanol. The absorbance was measured at $460 \mathrm{~nm}$ within the stability period of $35 \mathrm{~min}$ against the reagent blank prepared similarly. The reaction was achieved instantaneously. The absorbance of the resulting solutions was measured at $460 \mathrm{~nm}$ against reagent blanks treated similarly. Beer's law is obeyed in the concentration of $20-100 \mu \mathrm{g} / \mathrm{mL}$ of rabeprazole. Calibration curve was plotted from absorbance values against concentration of drug (Figure 1).

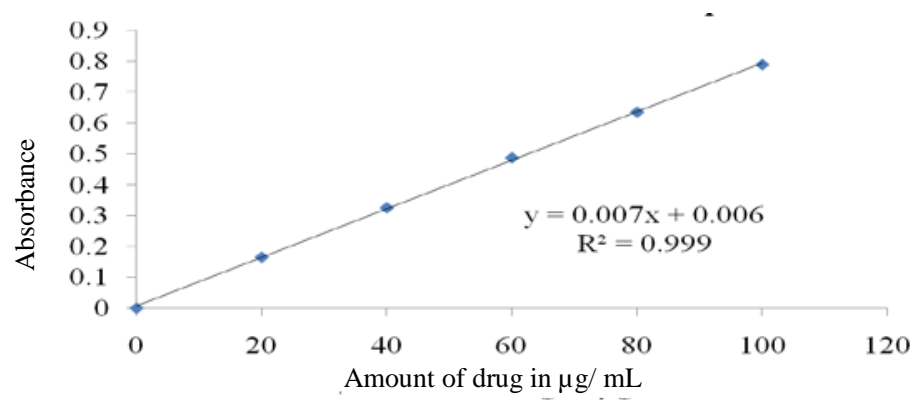

Figure 1. Calibration curve of rebeprazole

\section{Preparation of sample solution}

Twenty tablets of rabeprazole were accurately weighed and powdered. Tablet powder equivalent to $100 \mathrm{mg}$ of rabeprazole was dissolved in $50 \mathrm{~mL}$ of methanol, sonicated for $15 \mathrm{~min}$, filtered through whatman No. 1 filter paper and washed with methanol. The filtrate and washings were combined and the final volume was made to $100 \mathrm{~mL}$ with methanol. The solution was suitably diluted and analyzed as given under the assay procedure for bulk samples. The results are listed in Table 1 . 
Table 1. Assay of rabeprazole in tablet formulations

\begin{tabular}{cccccc}
\hline Tablets & $\begin{array}{c}\text { Labeled } \\
\text { amount, mg }\end{array}$ & $\begin{array}{c}{ }^{*} \text { Amount found } \\
(\mathrm{mg}) \pm \text { S.D }\end{array}$ & $\begin{array}{c}\text { \% label } \\
\text { claim }\end{array}$ & \%RSD & ${ }^{*}$ t value \\
\hline Tablet 1 & 20 & $20.01 \pm 0.22$ & 100.05 & 1.125 & 0.9930 \\
Tablet 2 & 20 & $20.04 \pm 0.12$ & 100.2 & 0.6082 & 0.7339 \\
Tablet 3 & 20 & $20.19 \pm 0.25$ & 100.95 & 1.282 & 1.642 \\
\hline
\end{tabular}

*Average of five determination based on label claim

\section{Results and Discussion}

The optimum conditions for the assay method were established by studying the reaction as a function of the concentration of reagent, the nature of the solvent and the stability of the coloured species. For the proposed method, the effect of the volume of $0.1 \%$ DDQ was studied over the range of $0.5-2.5 \mathrm{~mL}$ in a solution containing $100 \mu \mathrm{g} / \mathrm{mL}$ rabeprazole. The results revealed that $1.0 \mathrm{~mL}$ of DDQ was required to achieve the maximum intensity of colour. Therefore, $1.0 \mathrm{~mL}$ was used as an optimum value and maintained throughout the experiment. The reaction is stabilized within $2.0 \mathrm{~min}$ of mixing at room temperature and the absorbance remains constant for a further $35 \mathrm{~min}$. The method was based on the charge transfer complexation reactions of rabeprazole as $n$-electron donor with acceptor, 2,5-dichloro-3,6-dihydroxy-1,4-benzoquinone in methanol medium. The absorbance of the highly intensive coloured solution was measured at $460 \mathrm{~nm}$ against reagent blank treated similarly. The linear calibration curves were obtained over the concentration range of $20-100 \mu \mathrm{g} / \mathrm{mL}$ of rabeprazole. Statistical analysis was carried out and the results were found to be satisfactory. The optical characteristics such as absorption maxima, Beer's law limits, molar absorptivity and Sand ell's sensitivity are presented in Table 2. The regression analysis using the method of least squares was made for slope (b), intercept (a) and correlation obtained from different concentrations and the results are summarized in Table 1. The high molar absorptivities of the resulting colored complexes indicate the high sensitivity of the methods. The reproducibility, repeatability and accuracy of the proposed method were found to be satisfactory (Table 2) which is evidenced by low values of standard deviation, percent relative standard deviation. The percent recovery obtained indicates non interference from the excipients used in the formulations. In the student's ' $t$ ' tests, no significant differences were found between the calculated and theoretical values of the proposed method at 95\% confidence level. This indicated similar precision and accuracy in the analysis of rabeprazole in its tablets.

Table 2. Optical characteristics of the proposed methods

\begin{tabular}{lc}
\hline Parameters & Proposed method \\
\hline$\lambda \max (\mathrm{nm})$ & 400 \\
Beer's law limit $(\mu \mathrm{g} / \mathrm{mL})$ & $20-100$ \\
Molar absorptivity $\left(\mathrm{l} \mathrm{mole} \mathrm{C}^{2}{ }^{-1}\right)$ & $2.34 \times 10^{3}$ \\
Sandell's sensitivity $\left(\mu \mathrm{g} \mathrm{cm}^{2} / 0.001\right.$ absorbance & 0.0435 \\
unit) & \\
Regression equation $(\mathrm{Y}=\mathrm{a}+\mathrm{bx})$ & $\mathrm{Y}=0.007 \mathrm{X}+0.006$ \\
Slope (b) & 0.007 \\
Intercept (a) & 0.006 \\
correlation coefficient $(\mathrm{r})$ & 0.999 \\
\hline
\end{tabular}


Thus the method developed in the present investigation found to be simple, sensitive, accurate and precise and can be successfully applied for the estimation of rabeprazole in tablets.

\section{Conclusion}

Hence the proposed method is simple, cost effective and free from pollution. It is concluded that the described method has the potential for the application in the quality control laboratories.

\section{References}

1. Garcia C V, Sippel J, Garcia S S and Schapoval E E S, Int J Pharm Sci., 2010, 2(1), 468.

2. Zhang Y, Chen X and Zhong D, Anal Chim Acta, 2004, 523(2), 171-175.

3. Halder A, Mandal B K, Sridevi R and Navalgund S G, J Pharm Health Manag., 2011, 2, 76-82.

4. $\quad$ Uma Mahesh K and Sanjeeva Y, E-J Chem., 2010, 7(2), 569-577.

5. El-Gindy A, El-azby and Maher M M, J Pharm Biomed Anal, 2003, 31, 229-42.

6. Amol M, Bhandare, Amol A, Shitalkumar R and Patil S, Trade Acience Inc., 2008, 7(6), 1-7.

7. $\quad$ Syed AA and Ayesha Syeda, Indian J Pharm Sci., 2008, 70(4), 507-510.

8. Garcia C V, Sippel J, Steppe M and Schapoval E E S, Anal lett., 2007, 39(2), 341-348.

9. Patel B H, Patel M M, Patel J R and Suhagia B N, J Liq Chromatogr Rel Technol., 2007, 30(3), 439-445.

10. Tushar G, Barot, Vipul Prajapati, Pate P K, Bhoi D K and Patel L D, Int J Chem Tech Res., 2009, 1(4), 1345-1353.

11. Ramakrishna N V S, Vishwattam K N, Wuhu S and Kumar S S, J Chromatogr B, 2005, 816(1-2), 209-214.

12. Gandhi S V, Khan S I, Jadhav R T, Jadhav S S and Jadhav G A, J AOAC Int., 2009, 92(4), 1064-1067.

13. Bhavesh H P, Bhanubhai N S, Madhabhai M P and Jignesh R P, J Chrom Sci., 2008, 46, 10-14.

14. Bhavesh H Patel, Madhabhai M Patel, Jignesh R Patel and Bhanubhai N Suhagia, Anal lett., 2006, 39(2), 439-445.

15. Suganthi A, John S and Ravi T K, Indian J Pharm Sci., 2008, 70(3), 366-8.

16. Raval P B, Puranik M, Wadher S J and Yeole P G, Indian J Pharm Sci., 2008, 70(3), 386-90.

17. Gandhi S V, Khan S I, Jadhav R T, Jadhav S S and Jadhav G A, J AOAC Int., 2009, 92(4), 1064-7.

18. Sabnis S S, Dnvandev D N, Jadhav V Y and Gandhi S V, J AOAC Int., 91(2), 344-8.

19. Dinesh Sahu, Yogesh P, Agrawal, Neetu Sabarwal, Avnish Jain and Arun Gupta K, Asian J Biochem Pharma Res., 2011, 3(1), 13-21.

20. Shweta S Sabnis, Nilesh D Dhavale, Vijay Y Jadhav and Santosh V Gandhi, Mole Bio Spec., 2008, 69, 849-852.

21. Ramesh L S, Sanket D H, Ganesh K D, Charusheela Bansode A and Pravin Taiane S, Pharmaceutical Methods., 2011, 2(3), 193-197.

22. Mandhanya Mayank, Dubey Nitin, Chaturvedi S C and Jain D K, J Pharm Life Sci., 2011, 1(2), 113-117.

23. Pillai S and Singhvi I, Indian J Pharm Sci., 2008, 70(5), 658-661. 
24. Sabnis S S, Gandhi S V, Madgulkar A R and Bothara K G, Hindustan Antibiot Bull., 2008, 49-50(1-4), 34-38.

25. Nesrin K Ramadan, Heba M Mohamed and Azza A M, J Appl Pharm Sci., 2011, 1(9), 73-80.

26. Raj Prasad K and Rajesh Sharma, J Chem Pharm Res., 2010, 2(2), 186-196.

27. Patel A H, Patel J K, Patel K N, Rajput G C and Rajgor N B, Int J Pharm Biological Res., 2010, 1(1), 1-5.

28. Revathi Gunji, Rama Rao N and Venkata Suresh P, Int J Drug Dev Res., 2012, 4(1), 316-324.

29. Baldha R G, Patel Vandana B and Mayank Bapna, Int J Pharm Tech Res., 2010, 2(2), 1563-1568.

30. Pattanayak P, Sharma R and Chaturvedi S C, Anal lett., 2007, 40(12), 2288-2294. 